\title{
Extrativismo e comercialização de Sphagnum (veludo): características, implicações socioeconômicas e ecológicas e perspectivas ${ }^{(1)}$
}

\author{
RAQUEL R.B. NEGRELLE (2), SUELEN ELISABETH BORDIGNON (2), \\ MÁRCIA REGINA FERREIRA (2) e LEONARDO KUMAGAI SAMPAIO (2)
}

\begin{abstract}
RESUMO
Visando a contribuir para o melhor entendimento da atividade extrativista de Sphagnun spp. no Brasil, apresenta-se resultado de levantamento etnobotânico junto às comunidades extratoras inseridas na APA de Guaratuba, Paraná. Especificamente visou-se a caracterizar socioeconomicamente esta comunidade assim como sua dependência frente ao recurso foco. Buscou-se também detalhar esta atividade extrativista em termos de sistema de produção-consumo ou "cadeia de valor", traçando a sua evolução histórica e avaliando as perspectivas de sustentabilidade socioeconômica-ambiental da mesma. Foram registradas cinco espécies: S. capillifolium (Ehrh.) Hedw., S. cuspidatum Ehrh. ex Hoffm., S. erythrocalyx Hampe, $S$. perichaetiale Hampe e $S$. recurvum P. Beauv, com ocorrência natural na região de estudo e igualmente submetidas a intenso extrativismo frente à demanda do segmento floricultor. Discutem-se as implicações socioeconômicas e ambientais e perspectivas deste tipo de extrativismo.
\end{abstract}

Palavras-chaves: floricultura; musgo; plantas ornamentais; produtos florestais não madeiráveis; Floresta Atlântica.

\section{ABSTRACT \\ Sphagnum (velvet) wild harvesting and trade: characteristics, social-economic and environmental implications, and perspectives}

Aiming to contribute to the better understanding of the Sphagnum wild harvesting in Brazil, the results from an ethnobotany survey on a harvesting community at the Guaratuba Mun. (Paraná, State, Southern Brazil) are presented. Specifically, the objective was to characterize the community social-economic aspects as well as its dependence on the studied resource. The production-consumption system or value chain of this harvesting activity was also detailed, including the historic evolution of the harvesting and trade process and the evaluation of the perspectives of its social-economic and environmental sustainability. Five species were registered: S. capillifolium (Ehrh.) Hedw., S. cuspidatum Ehrh. ex Hoffm., S. erythrocalyx Hampe, S. perichaetiale Hampe e $S$. recurvum P. Beauv. All these are native species that grow spontaneously on that region and are intensively harvested by the local community. The social-economic and environmental implications as well as the perspectives of this kind of wild harvesting are discussed.

Keywords: floriculture; peatlands; ornamental plants; non wood forest products; Atlantic Forest.

\section{INTRODUÇÃO}

Briófitas do gênero Sphagnum são globalmente importantes devido à sua grande capacidade de formação de turfa (tipo de solo formado pela deposição e decomposição dos filídios, com alta concentração de carbono e acidez), que cobrem aproximadamente $3 \%$ da superfície da Terra (CHARMAN, 2002). As turfeiras participam na fundamental função de regular a dinâmica hidrológica, mantendo a qualidade da água doce e a integridade de ciclos hidrológicos, constituindo-se em verdadeiros reservatórios hídricos (MOORE, 2002; BULLOCK e ACREMAN, 2003). Adicionalmente, regulam a química atmosférica do planeta, atuando como fonte e sumidouro de carbono (GORHAM, 1991; DORREPAAL et al., 2006), além de prover habitat único para muitas espécies raras e endêmicas (CHARMAN, 2002) e preservar registros paleoambientais (BARBER, 1993).

A exploração extrativista do Sphagnum para atender propósitos humanos é milenar. Inicialmente, seu uso estava atrelado ao fornecimento de material combustível e fonte de energia em contexto doméstico. Usualmente, os locais drenados após a retirada da turfa eram transformados em campos agrícolas (ROOS, 1996). Gradativamente, foi-se ampliando este universo de usos e aplicações da turfa pelo ser humano, transformando este recurso em comercialmente rentável já no início da idade média (BORGER, 1990). Atualmente, a exploração deste recurso atende duas grandes categorias de uso: a) combustível e b) uso hortícola e outros (KEYS, 1992).

O Sphagnum é usado extensivamente em horticultura como condicionador de solo, cobertura de canteiros e substrato para produção de mudas, especialmente de plantas ornamentais (BATHER e MILLER, 1991; FERREIRA et al, 2001; BENEDETTO et al, 2003). Também é considerado um material extraordinário para acondicionamento de plantas, flores e vegetais frescos, para jardinagem hidropônica e para armazenamento de raízes e bulbos (WHINAM et al. 2003; DIAS e MENDES, 2005). Há registro, também, do emprego deste material na proteção de feridas, assim como na confecção industrial de fraldas e absorventes, sendo considerado mais adequado que o algodão devido ao seu potencial de retenção de água, sendo mais fresco e suave (GLIME, 2007; SAXENA e HARINDER, 2004). Adicionalmente, este recurso natural tem sido empregado como indicador ambiental de mudanças climáticas (TUBA et al., 2011), como biofiltro no monitoramento de poluição aérea industrial de metais pesados (HENRIQUES, 2005; GUT-

\footnotetext{
(1) Trabalho recebido para publicação em 16/04/2012 e aprovado em 08/04/2014

(2) Lab.OIKOS, Dep. Botânica UFPR Cx.Postal 1903181531990 Curitiba, PR
} 
BERLET, 1988) e como absorvente em derramamentos de óleo (ROCHEFORT, 2000).

A exploração exacerbada do Sphagnum, em escala comercial, tem gerado impactos tanto em nível específico quanto em nível sistêmico (CHAPMAN et al, 2003; POULIN et al., 2004; DÍAZ et al., 2008; TOUSIGNANT et al., 2010) ). O desconhecimento (ou o desrespeito) da capacidade de manutenção dos estoques naturais e da dinâmica dos ciclos de recomposição tem levado frequentemente à exaustão deste recurso (HALLINGBACK e TAN, 1996; HODGETTS, 1996; BCC, 2006).

A diminuição drástica do estoque de recurso leva também a impactos socioeconômicos importantes, dado seu valor na composição de renda de muitas comunidades, especialmente aquelas já fragilizadas socioeconomicamente (TICKTIN, 2004). A concepção do que se chama "manejo sustentável dos recursos naturais" surge, portanto, como alternativa viável de se priorizar o bem-estar atual e futuro da coletividade, dentro de uma visão de longo prazo, favorecendo tanto a produção econômica quanto perpetuação do recurso e consequente manutenção da diversidade (SACHS, 2004). Nesta perspectiva, o conhecimento das estratégias locais de uso histórico do recurso deve ser considerado como importante elemento para a proposição de técnicas sustentáveis de exploração. Inúmeros trabalhos têm sido feitos no sentido de demonstrar que este é o caminho viável e coerente a ser seguido (PLOTKIN e FAMOLARE, 1992; SIMPSON e CHRISTENSEN JR., 1997; ALEXIADES e SHANLEY, 2004) .

Na zona costeira do estado do Paraná, particularmente no interior da Baía de Guaratuba, registra-se o crescimento espontâneo de Sphagnum em distintas porções da restinga, especialmente em locais de solo arenoso úmido a encharcado e sem cobertura arbórea ("brejos de restinga"). Semelhantemente aos mallines ou pomponales encontrados no Chile e designados como turfeiras antropogênicas (; VALENZUELA-ROJAS e SCHLATTER, 2004; DÍAZ et al., 2007; DÍAZ et al., 2008), nestes locais não há a acumulação de turfa. Elas correspondem a áreas úmidas recentes, formadas após o corte raso de plantações de Pinus em sítios de drenagem pobre, onde o Sphagnum prolifera devido a sua grande capacidade de tolerar condições de alagamento. Sua presença pode retardar consideravelmente a recolonização arbórea (DÍAZ e ARMESTO, 2007).

Localmente designado por "veludo", o Sphagnum vivo encontrado nestes locais tem sido submetido à dinâmica crescente extrativista de modo a atender demanda do setor floricultor, que o utiliza tanto como substrato para bromélias e orquídeas como para confecção de arranjos ornamentais e enchimento da base de coroas fúnebres. A demanda extrativista crescente e o desconhecimento da biodiversidade disponível assim como da dinâmica de extrativismo e dinâmica natural de reposição deste recurso pode afetar severamente a disponibilidade futura do mesmo (VAN SETERS e PRICE, 2001; MCNEIL e WADDINGTON, 2003).

Assim, com vista a subsidiar o melhor entendimento da dinâmica extrativista visando ao estabelecimento de planos de manejo que possibilitem a sustentabilidade deste recurso, apresenta-se resultado de levantamento etnobotânico junto às comunidades extratoras inseridas na APA de
Guaratuba, Paraná. Especificamente visou-se a caracterizar esta comunidade em termos socioeconômicos assim como sua dependência frente ao recurso foco. Buscou-se também detalhar esta atividade extrativista em termos de sistema de produção-consumo (BELCHER, 1998) ou "cadeia de valor" (SCHRECKENBERG et al., 2001), avaliando sua perspectiva de sustentabilidade socioeconômica e ambiental.

\section{MATERIAL E MÉTODOS}

O estudo foi desenvolvido na zona rural do município de Guaratuba-PR (25 $52^{`} \mathrm{~S}$; 48 $43^{\circ} \mathrm{W}$ ), nas localidades de Descoberto e Empanturrado/ Rio Cedro, a aproximadamente $40 \mathrm{~km}$ do centro urbano do município. A partir da indicação de Balzon (2006), procederam-se visitas prévias à região do interior da Baía de Guaratuba, sendo estes locais identificados como de maior incidência de extrativismo de Sphanum spp. Ambos estão inseridos na APA (Área de Proteção Ambiental) de Guaratuba e abrigam vegetação classificada como Floresta Ombrófila Densa de Terras Baixas (VELOSO et al., 1991) (Fig.1).

As áreas específicas de extrativismo apresentavam-se caracteristicamente como áreas pioneiras, com vegetação herbácea e arbustiva bem desenvolvida, porém com inexpressiva representatividade de estrato arbóreo, em geral resultante de intervenção antrópica anterior para plantio de Pinus. Nesses locais, registrou-se predomínio de solos arenosos úmidos a encharcados, com abundante presença de Sphagnum spp. Esta região da planície é caracterizada como zona de instabilidade intermediária, sendo comumente recoberta por solos podzóis muito arenosos com presença de carapaças ferruginosas (SILVEIRA et al., 2005), inundáveis a partir de estreita influencia fluvial (IBGE, 1992). Os principais tipos de solos encontrados são Espodossolos, Neosolos, Quartzarenicos, Hidromórficos e Organossolos (RODERJAN et al., 2002), sendo geralmente pobres e pouco produtivos para atividades agrícolas.

O clima desta região é do tipo Af, superúmido, sem estação seca, sem ocorrência de geadas e com temperatura média nunca inferir aos $18^{\circ} \mathrm{C}$. A precipitação média no mês mais seco é acima de $60 \mathrm{~mm}$ (SONDA, 2002).

Para identificação botânica do recurso submetido a extrativismo procedeu-se coleta do mesmo nos locais de extrativismo, conforme indicação dos extratores locais. A metodologia de coleta e herborização do material briofítico foi segundo Yano (1989), sendo as amostras depositadas no Herbário UPCB da Universidade Federal do Paraná. Para identificação e classificação das espécies foram utilizados os trabalhos de Crum (1984), Yano et al. (1985) e Sharp et al. (1994).

A caracterização socioeconômica dos extratores e o detalhamento da atividade de coleta, beneficiamento e comercialização (cadeia de valor) foram obtidos a partir de entrevistas semiestruturadas individuais e coletivas junto aos extrativistas. Procedeu-se também o acompanhamento a campo das distintas fases de lida com o recurso. Os extrativistas foram identificados a partir de contato com as lideranças comunitárias e num continuo processo "bola de neve" (BIERNACKI e WALDORF, 1981). 


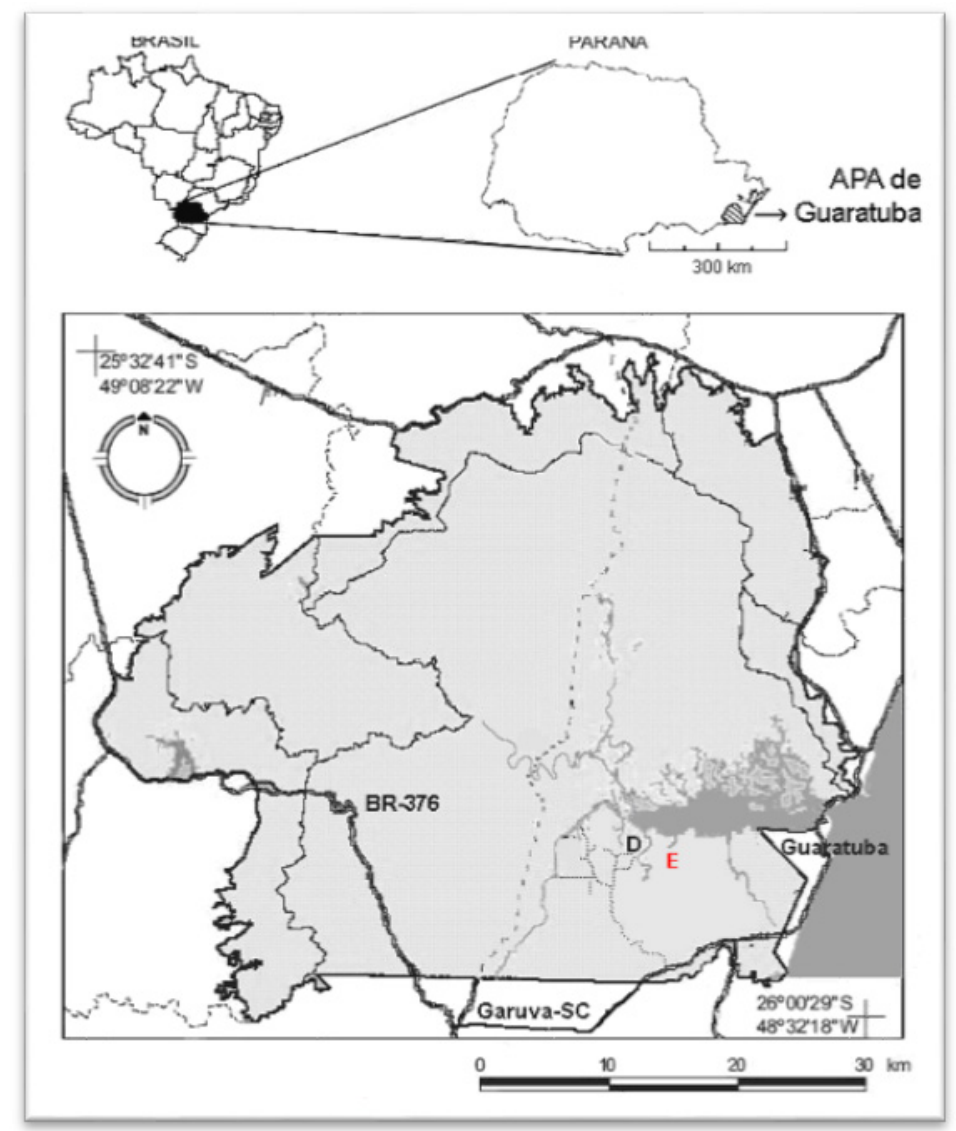

Figura 1. Localização da área de estudo: comunidades de Descoberto (D) e Empanturrado/ Rio Cedro (E) na APA de Guaratuba, litoral do estado do Paraná. (Mapa: Leonardo K.A. Sampaio, 2008).

Figure 1. Location of the study area: Descoberto (D) and Empanturrado/ Rio Cedro (E) communities at Guaratuba Environmental Protection Area, Parana State coastal area. (Map: Leonardo K.A. Sampaio, 2008).

\section{RESULTADOS}

\section{A comunidade extrativista}

No momento da realização da pesquisa, as comunidades de Descoberto e Empanturrado/ Rio Cedro abrigavam um total de 40 e 60 famílias, respectivamente. Estas famílias se definiam como "lavradores", sendo representadas por pequenos produtores de subsistência que se dedicavam ao cultivo de frutas, hortaliças e mandioca e criação de pequenos animais para consumo familiar. A renda média mensal familiar era cerca de $\mathrm{R} \$ 200$, advinda de venda esporádica de recursos provenientes de distintas atividades (pesca, agricultura e extrativismo), incluindo o Sphagnum (veludo). A venda desses produtos possibilitava a compra de mercadorias que garantiam sua subsistência.

Do total de 100 famílias, 28\% incluíam um ou mais extratores regulares de veludo (71\% em Empanturrado/Rio do Cedro). Para a grande maioria destas famílias, o extrativismo de veludo representava o ingresso financeiro mais importante e, em alguns casos, praticamente a única forma de obtenção de renda. Cerca de $80 \%$ da atividade de extrativismo era feita pelas mulheres, algumas vezes acompanhadas pelos filhos, enquanto os homens trabalhavam na pesca ou na agricultura.

Em geral, os extratores não possuíam a titularidade da terra onde viviam e cultivavam, sendo considerados pos- seiros de áreas com tamanho médio de 0,7 ha por unidade familiar. Em sua totalidade, eram descendentes de moradores antigos da própria região, mantendo muitas das práticas que aprenderam com seus pais e avós, incluindo o extrativismo de recursos florestais de seu entorno. O nível de escolaridade era baixo, correspondendo quando muito ao ensino fundamental incompleto.

Segundo Begossi (1999), as comunidades estudadas inserem-se na categoria de comunidades caiçaras. De acordo a Sonda (2002), as comunidades caiçaras de Descoberto e Empanturrado/ Rio Cedro podem ser consideradas como mais integradas ao mercado, comparativamente a outras situadas no interior e ao norte da baía de Guaratuba, devido a contar com bons acessos, tanto hidroviário como rodoviário, incluindo estradas abertas pela Comfloresta - Cia Catarinense de Empreendimentos Florestais para exploração florestal e contar com uma linha municipal regular de ônibus.

\section{O recurso extraído}

Segundo os extratores locais, a região estudada abrigava três tipologias distintas de veludo, a saber: a) "macarrão" ou "camarão", caracterizado pela cor verde paleácea a castanho avermelhado e ramos mais longos; b) "vermelho", correspondente a indivíduos menores de cor avermelhada e c) "verde", com cor verde-paleácea. A partir da coleta e 
análise do material briofítico, foram identificadas cinco espécies do gênero Sphagnum, sendo duas destas englobadas na tipologia "macarrão" (S. erythrocalyx Hampe - UPCB 59442 e $S$. perichaetiale Hampe - UPCB 59443), uma na tipologia "vermelho" (S. capillifolium (Ehrh.) Hedw UPCB 59444) e duas na tipologia "verde" (S. cuspidatum Ehrh. ex Hoffm - UPCB 59445 e S. recurvum P. Beauv.UPCB 59446). (Fig. 2)

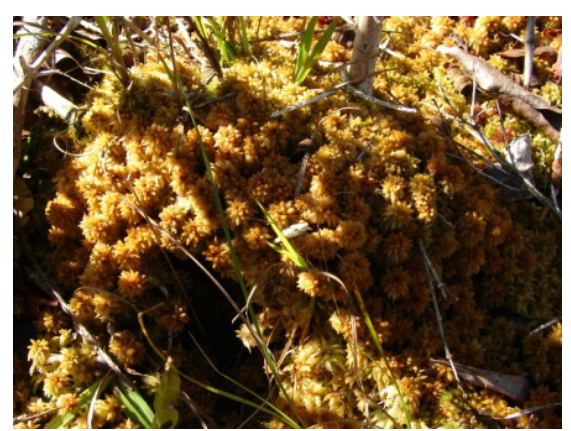

a)

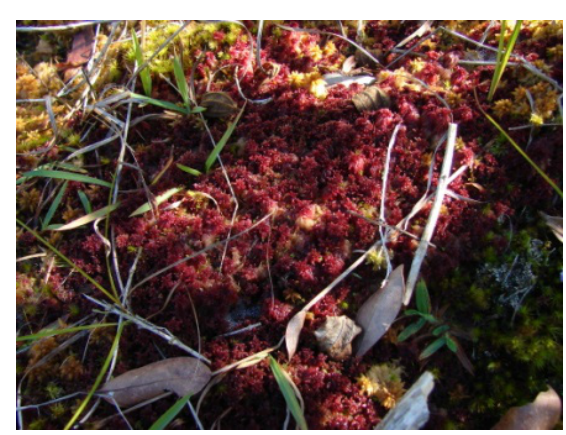

b)

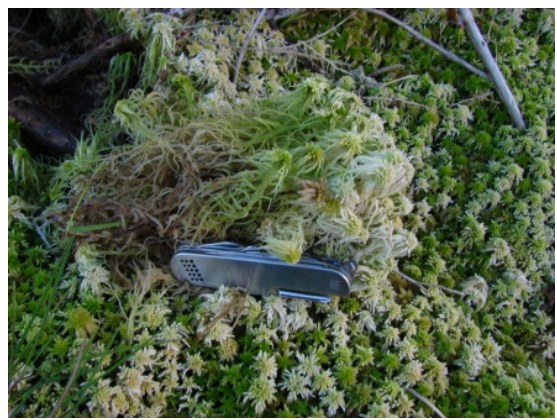

c)

Figura 2. Tipologias de Sphagnum identificadas pelos extratores das comunidades de Descoberto e Empanturrado, Mun. Guaratuba, Paraná: a) macarrão ou camarão (S. perichaetiale e S. erythrocalyx); b) vermelho (S. capillifolium) e c) verde (S. cuspidatum e S. recurvum). (Fotos: Leonardo Sampaio, 2008).

Figure 2. Sphagnum types identified by the harvesters from Descoberto and Empanturrado communities, Guaratuba Municipality, Paraná State: a) macaroni or shrimp ( . perichaetiale and S. erythrocalyx); b) red

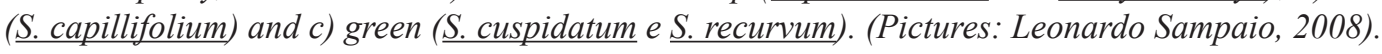

Todas as cinco espécies identificadas na região de estudo encontravam-se crescendo abundantemente em área de regeneração recente após corte de plantação de Pinus. Com a continuidade do desenvolvimento da cobertura florestal, e consequente maior sombreamento, há possibilidade de efeito deletério sobre o crescimento destas espécies de Sphagnun, dado que aparentemente preferem locais com grande disponibilidade de luz.

\section{Locais de coleta}

A coleta do veludo geralmente ocorria em locais bem afastados das residências dos coletores em áreas de reflorestamento da empresa Comfloresta - Cia Catarinense de Empreendimentos Florestais. A empresa tem a posse de grandes áreas na região sem, contudo, haver concluído a regularização fundiária, mas limitava o acesso a estas áreas. Havia, no entanto, certo acordo velado com os moradores locais, geralmente permitindo que estes realizassem o extrativismo nessas áreas. Como a atividade não podia ser feita em um mesmo local por muito tempo, devido à necessidade de regeneração do recurso, os coletores realizavam uma espécie de revezamento entre as áreas de coleta; coletando uma quantidade possível naquele local e, quando o recurso já estava escasso, os coletores migravam para o outro local. Segundo os extratores, após esse processo de extração, a área necessitava de um tempo mínimo de seis meses para voltar a ser explorada. Devido ao revezamento entre as áreas, os extratores chegavam a percorrer cerca de $6 \mathrm{~km}$ até o local de coleta, totalizando em média $12 \mathrm{~km} /$ dia. Este deslocamento entre a residência dos extratores e locais de coleta era usualmente realizado com bicicleta ou a pé.

\section{Caracterização geral do processo extrativista}

O extrativismo registrado nas comunidades de Descoberto e Empanturrado/ Rio Cedro era clandestino, dado que não estava associado a nenhum tipo de licenciamento ou autorização para a coleta de plantas junto ao órgão competente (IAP).

Os extratores locais praticavam um manejo empírico, no qual retiravam apenas certa quantidade de veludo, mantendo uma porção deste para futura regeneração do mesmo. O tempo de regeneração, segundo estes extratores, variava muito dependendo principalmente da intensidade de extração. Retirando-se apenas indivíduos de maiores dimensões e deixando-se uma matriz de indivíduos imaturos, o tempo de regeneração observado seria de aproximadamente um ano. Caso não fosse preservada esta matriz, o que não era raro de acontecer frente à crescente demanda, este tempo poderia ampliar-se para até três anos. Neste caso, havia contínua busca por novas áreas de coleta.

A lida com o veludo era realizada normalmente todos os dias da semana, tomando o dia inteiro de trabalho, diminuindo apenas nos dias de chuva, dada a dificuldade de secagem.

A coleta era realizada de forma manual, com ajuda eventual de equipamentos simples como canivete e facões. Segundo os extratores, em área de $3 \mathrm{~m}$ x $2 \mathrm{~m}\left(6 \mathrm{~m}^{2}\right)$ eram retirados dois sacos de musgo fresco. Com trabalho intenso, cada extrator (mais um membro da família) tirava em média 20 sacos/dia (Fig.3). Em um primeiro momento, o material coletado era agrupado em áreas próximas aos locais de coleta, sobre ramos suspensos, para eliminar o excesso de água. Ao final da coleta, o extrator repassava estes locais, ensacando o material coletado para transportá-lo até sua residência, utilizando bicicleta ou carrinho de mão. Para tanto, utilizavam sacos de polietileno (saco de adubo), por serem mais resistentes. Cada saco cheio de musgo fresco pesava cerca de $4 \mathrm{~kg}$ Em cada viagem eram transportados em média cinco sacos, totalizando até quatro viagens do local de coleta até a casa do extrato onde era realizado o processo de secagem. Entre coleta e transporte, a lida com 20 sacos de veludo tomava pelo menos dois dias (Fig. 3). 
No quintal de sua residência, procedia a limpeza do veludo, retirando materiais indesejáveis após colocá-lo para secar sobre lonas ou outro material impermeável estendido a céu aberto. Em dias ensolarados, a secagem levava em torno de 24 horas. Geralmente esse processo era feito concomitantemente ao processo de transporte dos sacos do local de coleta à residência, revolvendo-se constantemente o veludo sobre a lona para que o material secasse homogeneamente. Em caso de chuva, o material posto para secar era recolhido e guardado em lugar seco até a chuva parar. Cada dois sacos de musgo fresco rendiam um saco de musgo seco.
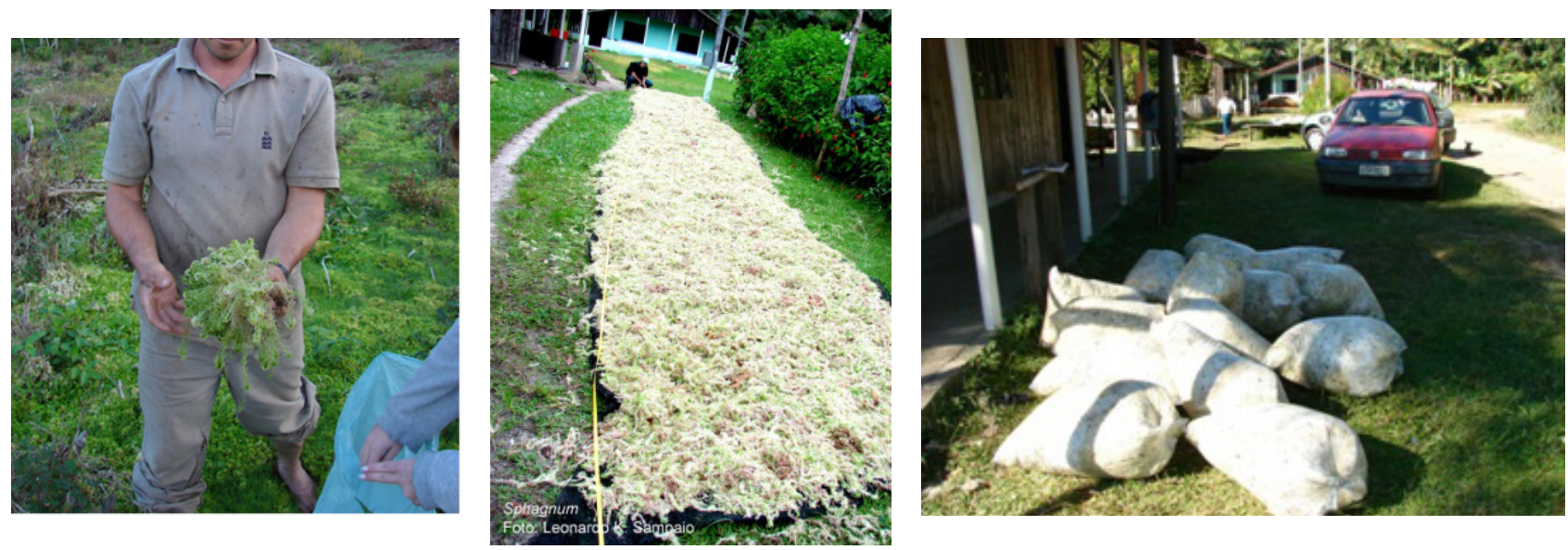

Figura 3. Extrativismo de Sphagnum registrado na APA de Guaratuba, Paraná: coleta, secagem e embalagem. (Fotos: Leonardo Sampaio, 2008).

Figure 3. Sphagnum wild harvesting registered at the Guaratuba Environmental Protection Area, Parana State: harvesting, drying and packing. (Pictures: Leonardo Sampaio, 2008).

\section{Comercialização}

O produto era comercializado in natura, sem nenhum processo de beneficiamento além da secagem. A venda era realizada na casa do extrator, em embalagens (sacos plásticos de 80 litros) que comportavam cerca de $4 \mathrm{~kg}$ de veludo seco. $\mathrm{O}$ comprador/ intermediário era quem fornecia a embalagem para acondicionamento e comercialização do veludo assim como o valor a ser pago ( $\mathrm{R} \$ 2,00 /$ saco), estabelecendo geralmente a demanda de coleta. Eram necessários dois membros das famílias e quatro dias de trabalho para obter uma renda de $\mathrm{R} \$ 40,00$, ou seja, duas pessoas trabalhando constantemente para receber R\$ 5,00 cada uma por dia de trabalho (Fig.4).

\begin{tabular}{|c|c|c|c|c|}
\hline Etapa & $\begin{array}{l}\text { Pessoas } \\
\text { Envolvidas }\end{array}$ & $\begin{array}{l}\text { Material } \\
\text { Utilizado }\end{array}$ & 9 & Volume \\
\hline $\begin{array}{l}12 \\
\text { Coleta na Fl }\end{array}$ & & Sacos & $8 \mathrm{~h}$ & 20 sacos \\
\hline $\begin{array}{l}29 \\
\text { Transporte }\end{array}$ & $\dot{0}$ & $\begin{array}{l}\text { Bicicleta ou } \\
\text { carrinho-de-mão }\end{array}$ & 2 dias & $\begin{array}{l}5 \text { sacos/ } \\
\text { viagem }\end{array}$ \\
\hline $\begin{array}{l}32 \\
\text { Secagem }\end{array}$ & $\dot{\mathbf{m}}$ & Lona, Tela & $12 \mathrm{~h}$ & 20 sacos \\
\hline $\begin{array}{l}49 \\
\text { Empacotar }\end{array}$ & $\dot{\theta}$ & Saco e corda & $\begin{array}{l}30 \\
\min .\end{array}$ & 20 sacos \\
\hline
\end{tabular}

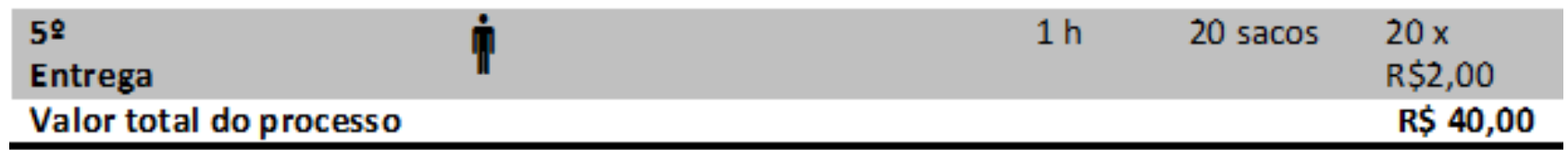

Figura 4. Etapas relacionadas ao extrativismo e comercialização de Sphagnum registrados na APA de Guaratuba, Paraná.

Figure 4. Phases of Sphagnum wild harvesting and trade registered at the Guaratuba Environmental Protection Area, Parana State. 
Os compradores/ intermediários não compravam exclusivamente veludo, percorrendo a região em busca de outros produtos ofertados por comunidades da região, como por exemplo, cipó-preto (Philodendron corcovadense Kunth) e palha (Geonoma gamiova Barb. Rodr). A vinda do comprador de veludo era irregular, podendo ser semanalmente, quinzenalmente ou até mensalmente. Apenas uma família da comunidade relatou que levava o produto até a cidade mais próxima (Guaratuba) para comercialização, recebendo o dobro por uma mesma quantidade vendida ao intermediário que ia até a comunidade.

Geralmente, o comprador/ intermediário funcionava também como atacadista distribuindo o veludo junto a floriculturas e lojas de artesanato da região metropolitana de Curitiba e Santa Catarina. Nestes estabelecimentos, o veludo era principalmente utilizado como material de enchimento para a base de sustentação de arranjos florais e coroas fúnebres, estes vendidos diretamente ao consumidor final (Fig.5). Em alguns casos, o comprador/ intermediário vendia para atacadistas de Campinas e Rio Grande do Sul e estes, por sua vez, distribuíam a varejistas locais. O comprador/intermediário comprava o saco de veludo a $R \$ 2,00$ e o revendia por $R \$ 7,00$ para as floriculturas.
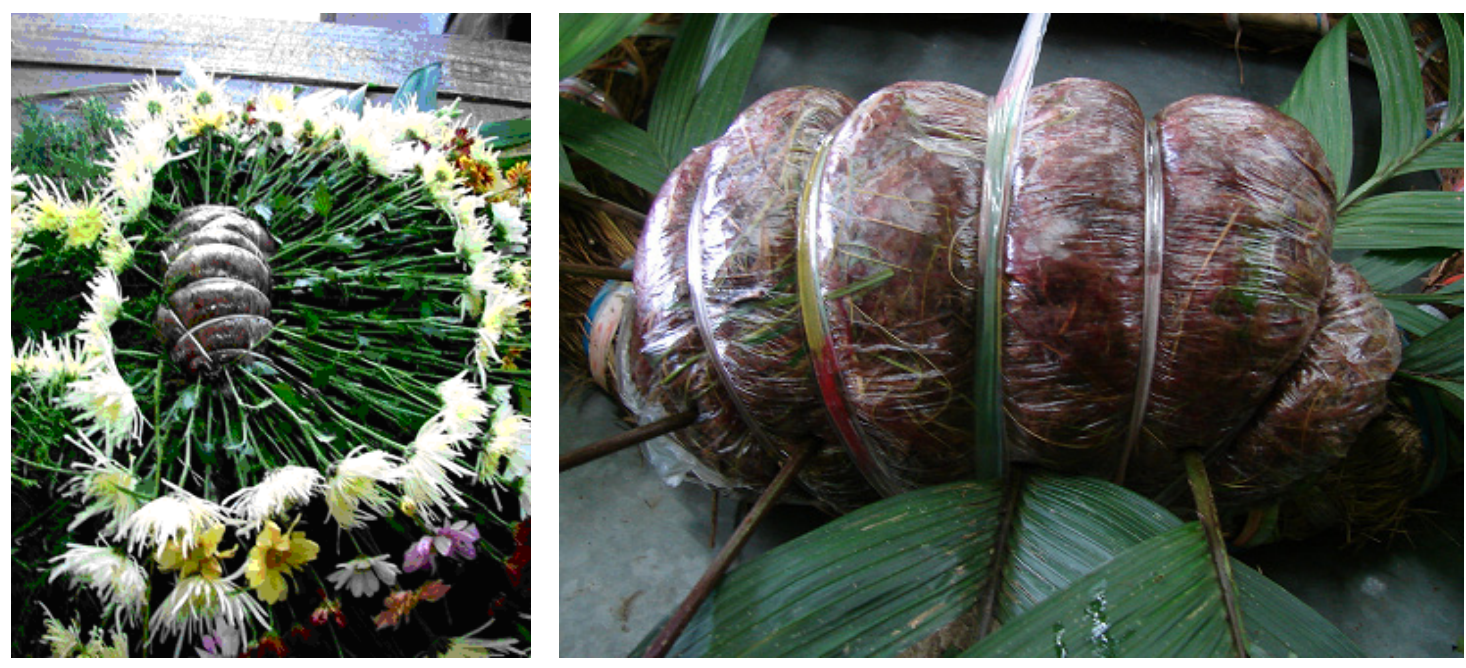

Figura 5. Utilização de Sphagnum como enchimento da base de arranjos florais e fúnebres em floricultura de Curitiba, Paraná. (Fotos: Leonardo Sampaio, 2008)

Figure 5. Sphagnum used for filling the base of floral and funeral arrangements at floral shops in Curitiba, Paraná.

\section{DISCUSSÃO}

\section{Implicações socioeconômicas}

O extrativismo clandestino praticado por alguns extratores de Sphagnum pode ser categorizado como "estratégia diversificada", conforme Belcher et al. (2005). Ou seja, o extrativismo estava integrado a outras atividades praticadas nas áreas onde residiam e seu entorno, que em sua pluralidade configuravam a subsistência/rendimento familiar. Por outro lado, a maioria dos extratores enquadrava-se na "estratégia de adaptação". Neste caso, o extrativismo era a única fonte de renda familiar, mas o rendimento advinha de vários produtos extraídos da natureza e, em geral, era abaixo de um salário mínimo. A opção extrativista resultava da precária capacitação pessoal e falta ou limitada oferta de outras oportunidades de emprego. Em ambos os casos, estes extrativistas podem ser categorizados como "empreendedores viradores" (SOUZA NETO, 2008), ou seja, este tipo de empreendedores, ao invés de optar pelo empreendimento próprio por vocação ou por ter descoberto uma oportunidade no mercado, o fazem por necessidade (SILVA e PEREIRA, 2007). Os principais condicionantes desta situação são o desemprego e as restrições ambientais associadas a unidades de conservação ambiental, tornando ainda mais precárias as condições de possibilidade de re- produção social e econômica destes extratores (DUMORA, 2006; FERREIRA, 2010).

Esta dinâmica caracterizava uma produção mercantil simples em uma economia não-capitalista, denominada economia familiar ou campesina, segundo Moura (1986). Na economia capitalista, que envolve renda bruta, material, salário, o lucro líquido precisa ser maior que zero para ser viável a produção. Na economia campesina existe apenas o binômio: trabalhador e meio de produção, onde a venda de uma mercadoria (PFNM) resulta em dinheiro para adquirir outra mercadoria (arroz, material escolar, roupa), garantindo a subsistência.

Por sua vez, a interação identificada entre a comunidade extratora e os compradores caracterizava um mercado oligopsônico, ou seja, poucos compradores e muitos vendedores de um mesmo produto. No caso do mercado oligopsônico (poucos compradores) ou monopsônico (um único comprador), quem fixa o preço é o mercado (SINGER, 2001), resultando uma relação econômica extremamente negativa, devido à exploração do trabalho e do tempo dedicado a essas atividades pelas famílias. Afinal, quem define o valor a ser pago é o intermediário.

Via de regra, a comunidade extratora tem precário acesso ao mercado, insuficiente capital humano, insuficiente capital produtivo, instituições fracas e, geralmente, fraco 
poder de barganha (BELCHER et al., 2005; HOMMA, 2008). O empreendedorismo, nessa perspectiva, faz com que os extrativistas participem de um círculo vicioso e perverso: extraem porque são pobres e sem alternativas e, por serem pobres e sem alternativas, extraem (BELCHER et al,. 2005; JUNKIN et al., 2005)

\section{Implicações ambientais}

No seu estado natural, o tapete de Sphagnum influencia a hidrologia, essencialmente em termos de fornecimento de água e a sua regulação. Durante períodos de elevada precipitação, a quantidade de água armazenada na camada activa do ecossistema aumenta substancialmente, esta água é libertada gradualmente durante os períodos de baixa precipitação. O resultado é a regulação do ciclo hídrico em vários níveis: (1) regulando a infiltração, através de uma cedência gradual e contínua para os níveis inferiores da água que intercepta; (2) regulando a escorrência superficial e subterrânea e, consequentemente, dos caudais das nascentes; (3) regulando a escorrência superficial evita o aumento rápido dos caudais após os picos de precipitação; (4) regula a erosão dos solos; (5) regulando o micro-clima local, na medida em que proporciona uma evapotranspiração real muito elevada, contínua e com baixa variação anual (BULLOCK e ACREMAN, 2003; McNEIL e WADDINGTON, 2003; DORREPAAL et al.; 2006).

Segundo DIAS e MENDES (2005), a remoção do tapete de Sphagnum poderá dar origem, a curto prazo, a um aumento brusco da escorrência superficial, associado a grandes prejuízos; a acentuada remoção e erosão dos solos associado a uma descaracterização da paisagem e a uma importante diminuição no volume de água interceptada e retido na cobertura. A longo prazo poderá provocar: diminuição da recarga dos aquíferos; alteração do regime de recarga que poderá evoluir de um regime aproximadamente constante ao longo do ano para um regime sazonal; alteração das características químicas da água, até então de ótima qualidade, poderá evoluir para situações de contaminação e alteração do micro-clima. Esta dinâmica de resposta à remoção tem fortes implicações sobre a conservação da biodiversidade local.

Geralmente, os sítios abandonados após intensa ação extrativista raramente retornam a ecossistemas funcionais. As alterações no sistema de drenagem, o consequente aprofundamento do lençol freático e exposição do solo impossibilitam o restabelecimento natural da turfeira (CAMPEAU e ROCHEFORT;1996; VAN SETERS e PRICE, 2001).

Entretanto, a percepção social sobre o real impacto da perda da diversidade não é fácil de ser estabelecida. As alterações severas nos ecossistemas naturais, apesar do alto custo ecológico, representam também benefícios sociais e econômicos bastante visíveis, facilmente mensuráveis e praticamente imediatos. Por outro lado, o balanço objetivo destes custos ecológicos, normalmente só explicitados em longo prazo, é extremamente difícil de ser realizado (SOLBRIG, 1991). A conservação dos recursos naturais deve, portanto, ser tratada como uma questão social. Muitos ambientalistas e conservacionistas experientes têm evidenciado que o êxito de projetos conservacionistas está diretamente vinculado ao interesse e envolvimento da comunidade afetada. Projetos de conservação maravilhosamente bem desenhados, mas que não contemplem esta visão participativa e de envolvimento da comunidade, assim como de alternativas socioeconômicas viáveis, certamente estarão fadados ao insucesso (ALEXIADES e SHANLEY, 2004; KUSTER e BELCHER, 2004)

\section{Aspectos sócio-políticos e institucionais}

O extrativismo de Sphagnum, assim como de outros produtos florestais não madeiráveis, com fins comerciais, não é absolutamente proibido pelas leis ambientais brasileiras. A Lei $\mathrm{n}^{\circ} 11.428$, de 22 de dezembro de 2006, que dispõe sobre a utilização e proteção da vegetação nativa do Bioma Mata Atlântica, estabelece que:

Art. 18. No Bioma Mata Atlântica, é livre a coleta de subprodutos florestais tais como frutos, folhas ou sementes, bem como as atividades de uso indireto, desde que não coloquem em risco as espécies da fauna e flora, observando-se as limitações legais específicas e em particular as relativas ao acesso ao patrimônio genético, à proteção e ao acesso ao conhecimento tradicional associado e de biossegurança.

Por sua vez, o Decreto $\mathrm{n}^{0} 6.660$, de 21 de novembro de 2008, que regulamenta dispositivos da Lei no 11.428 , estabelece que:

Art. $2^{\circ}$ A exploração eventual, sem propósito comercial direto ou indireto, de espécies da flora nativa provenientes de formações naturais, para consumo nas propriedades rurais, posses das populações tradicionais ou de pequenos produtores rurais, de que trata o art. 9 o da Lei no 11.428, de 2006, independe de autorização dos órgãos competentes.

$\S 4^{\circ}$ A exploração de matéria-prima florestal nativa para uso no processamento de produtos ou subprodutos destinados à comercialização, tais como lenha para secagem ou processamento de folhas, frutos e sementes, assim como a exploração de matéria-prima florestal nativa para fabricação de artefatos de madeira para comercialização, entre outros, dependerá de autorização do órgão ambiental competente, observado o disposto neste Decreto.

Desta forma, a legalização do extrativismo com fins comerciais é dependente de licenciamento auferido pelo órgão ambiental competente que, no caso do Estado do Paraná, corresponde ao Instituto Ambiental do Paraná- IAP. Nesta perspectiva, em 2008, foi instituído pelo IAP o "Grupo de Trabalho Legislação Conservacionista para Agricultura Familiar do Paraná" que, dentre suas atribuições, visava discutir o tema extrativismo assim subsidiar a regulamentação deste. No entanto, até o momento o assunto permanece sem resposta oficial por parte daquela entidade. Assim, é praticamente impossível obter o devido licenciamento para o extrativismo comercial no estado do Paraná.

Uma alternativa seria formalizar o pedido de licenciamento junto ao IAP, recorrendo ao decreto $\mathrm{n}^{\circ} 6.660$, de 21 de novembro de 2008, especificamente ao Art. 47, que estabelece:

O extrativismo sustentável e a comercialização de produtos e subprodutos oriundos de remanescentes da Mata Atlântica, quando realizados por pequenos produtores rurais e populações tradicionais, poderão integrar Sistemas Participativos de Garantia da Qualidade Orgânica, desde que atendidos os requisitos estabelecidos no Decreto no 6.323, de 2007. 
No entanto, segundo técnicos do IAP consultados sobre o tema, dificilmente o órgão saberá dar uma resposta a contento frente a esta demanda. Este tema é novo e a falta de definição oficial não oferece o respaldo necessário para o técnico emitir seu parecer.

\section{Perspectivas}

Se houver continuidade no revezamento das áreas de coleta, respeitando-se a dinâmica natural de reposição do recurso, o extrativismo do veludo nas comunidades estudadas é potencialmente sustentável (WHINAM e BUXTON, 1997; RAMSAR, 2007), podendo inclusive contribuir para a conservação da biodiversidade local (CHAPMAN et al., 2003).

No entanto, dado que o mercado determina o volume e a frequência de coleta, assim como o ingresso de renda aos extrativistas, há o risco de esta dinâmica extrativista sustentável vir a ser debilitada. Enquanto o mercado for pequeno, o setor extrativo sobrevive. No entanto, a sustentabilidade do extrativismo será improvável se o mercado for muito ampliado (HOMMA, 2008).

Para que o veludo seja efetivamente apresentado como alternativa economicamente viável e ecologicamente sustentável, devem ser estabelecidos planos de manejo sustentável para este recurso, com monitoramento em longo prazo da dinâmica de reposição do mesmo. Outro componente imprescindível, nesta perspectiva, engloba a domesticação e o estabelecimento de unidades de cultivo destas espécies (ver WICHTMANN e JOOSTEN, 2007; BLIEVERNICHT et al., 2011), com vistas a prover bases seguras para o atendimento das demandas crescentes de mercado assim como para a redução da pressão de extrativismo e respectivos impactos negativos, conforme apontado em Homma (2008). Igualmente importante é a conscientização destas comunidades rurais acerca da vulnerabilidade do extrativismo não adequadamente planejado. Como apontado em Rancura (2009), a organização comunitária e a legalização da atividade são passos essenciais neste sentido.

Comunidades extrativistas desagregadas e/ ou pouco organizadas frequentemente são palco da "tragédia dos comuns", ou seja, da exaustão do recurso comum a partir da ação individual independente e voltada para somente interesses particulares (HARDIN, 1968). No entanto, os usuários de um determinado recurso podem organizar-se e cooperar para conservar este recurso em nome do benefício mútuo. Ou seja, comunidades extrativistas organizadas são capazes de criar instituições voltadas à regulação dos seus membros em relação ao uso compartilhado do recurso comum de forma sustentável, sem que se atinja a "tragédia" (OSTROM, 2000).

Na ausência de auto-organização comunitária, alguma forma de intervenção externa é necessária para resolver o problema da ação coletiva sobre dado recurso. Neste caso, particularmente se aplicam as regulamentações governamentais que definem regras explícitas sobre o acesso individual de recursos comuns, sem, contudo, promover constrangimentos aos indivíduos ou favorecer determinados grupos em detrimento de outros menos favorecidos (CUNHA, 2004).

Por outro lado, o reconhecimento social e legal da atividade extrativista, praticada de forma adequada e com o amparo técnico devido, determinando efetiva melhoria no modo de vida das famílias caiçaras, somente será possível se as instituições públicas competentes desenvolverem uma visão socioambiental em relação aos territórios ocupados por elas (SANTILLI, 2005; SYLVESTER e AVALOS, 2009). Atualmente, evidencia-se o Estado apenas como instituição de regulação (como por exemplo, por meio do IAP) ou de controle e fiscalização (por meio da Polícia Ambiental Força Verde).

As comunidades caiçaras extrativistas embora, muitas vezes, corporifiquem um modo de vida tradicionalmente mais harmonioso com o ambiente, são persistentemente desprezadas e afastadas de qualquer contribuição que poderiam oferecer à elaboração de políticas públicas regionais (ARRUDA, 1999). As comunidades extrativistas ainda permanecem "invisíveis" para o Poder Público, em razão de seu fraco poder econômico e ausência de organização e representatividade política (FERREIRA et al., 2011). A saída da informalidade requer um conjunto de políticas públicas complementares inspiradas pelo princípio de tratamento desigual dos desiguais, no caso, ações afirmativas em favor destes empreendedores mais fracos, para que possam, com o tempo, enfrentar o mercado em condições de competitividade genuína e de produtividade suficiente para proporcionar postos de trabalho decente (SACHS, 2004).

Neste contexto, conforme apontado em Belcher et al. (2005), adicionalmente enfatiza-se que a chave para o sucesso de qualquer empreendimento relacionado ao extrativismo de produtos florestais não madeiráveis (PFNM), incluindo o Sphagnum, deve prioritariamente considerar os seguintes aspectos:

A exploração destes recursos deve estar integrada a outras atividades econômicas;

Comunidades pobres são pobres porque têm precário acesso a mercados, insuficiente capital humano, insuficiente capital produtivo, instituições fracas e, geralmente, fraco poder de barganha;

Alguns PFNM oferecem grande potencial de criação de empregos e oportunidades de renda, mas transformar este potencial em realidade requer investimentos em capacitação humana, promoção de associativismo, melhoria nas condições de acesso ao recurso e do acesso deste aos potenciais mercados, entre outros aspectos;

A participação comunitária, em todas as etapas de concepção e execução, é uma das bases do sucesso de projetos desta natureza;

Os sistemas de intervenção devem ser propostos a partir de delineamento interdisciplinar abrangendo as dimensões ecológica, social, institucional, política e de mercado;

A extração comercial de PFNM em si não é uma proposta direta para a melhoria da qualidade de vida das famílias com vulnerabilidade social em áreas rurais. A comercialização exitosa ocorre em conjunto com outras atividades políticas, sociais e econômicas.

\section{AGRADECIMENTOS}

Aos extratores de veludo das comunidades de Descoberto e Empanturrado/ Rio Cedro, especialmente ao Sr. Manoel Gaudino e Sra. Célia Regina de Jesus, por sua disponibilidade em acompanhar o trabalho de coleta de material assim como por compartilhar conosco suas experiências e vivências relacionadas ao extrativismo deste recurso. A Dra. Olga Yano (Seção de Briologia e Pteridologia, Instituto de Botânica/ SP), pelo auxílio na identificação botânica das espécies 
de Sphagnum. À Secretaria de Estado da Ciência, Tecnologia e Ensino Superior (SETI)- Programa Universidade Sem Fronteiras; Sub-Programa Apoio à Agricultura Familiar pelo apoio financeiro para realização da pesquisa.

\section{REFERÊNCIAS}

ALEXIADES, M.; SHANLEY, P. (org.) Productos forestales, medios de subsistencia y conservación: America Latina. Indonesia: CIFOR, 2004. 499p.

ARRUDA, R. Populações tradicionais e a proteção dos recursos naturais em unidades

de conservação. Ambiente e Sociedade, São Paulo, v. 2, n. 5, p. 79-92, 1999.

BALZON, D. R. Avaliação econômica dos produtos florestais não madeiráveis na área de proteção ambiental APA de Guaratuba - Paraná. Curitiba, UFPR, 2006. 176p. Tese (Doutorado em Engenharia Florestal).

BARBER, K. E. Peatlands as scientific archives of past biodiversity. Biodiversity and Conservation, London, v.2, n. 5, p. 474-489, 1993.

BATHER, D. M.; MILlER, F. A. Peatland utilisation in the British Isles. Reading: Centre for Agricultural Strategy, 1991, 64p.

BCC- THE BRYOPHYTE CONSERVATION COMMITTEE. Biennial report from members 2005-2006. Disponível em:

http://www.artdata.slu.se/guest/SSCBryo/files/Report_fr Bryophyte_Conservation_Committee_2005-6.pdf. Acesso em: 22 de março de 2012.

BEGOSSI, A. Caiçaras, caboclos and natural resources: rulles and scale patterns. Revista Ambiente \& Sociedade, São Paulo, n. 5, p.55-67, 1999.

BELCHER, B. A production to consumption systems approach: lessons from the bamboo and rattan sectors in Asia. In: WOLLENBERG, R.; INGLES, A. (eds.). Incomes from the forest: methods for the development and conservation of forest products for local communities. Indonesia: CIFOR, p. 57-84, 1998.

BELCHER, B.; RUÍZ-PÉREZ, M.; ACHDIAWAN, R. Global patterns and trends in the use and management of commercial NTFPs: Implications for livelihoods and conservation. World Development, Ottawa, v. 33, n. 9, p. 1435$1452,2005$.

BENEDETTO, A.; BOSCHI, C.; KLASMAN, R.; MOLINARI, J. El crescimento de cuatro plantas ornamentales anuales em diferentes substratos. Revista Brasileira de Horticultura Ornamental, Campinas, v. 9, n. 2, p. 171-177, 2003.
BIERNACKI, P.; WALDORF, D. Snowball sampling-problems and techniques of chain referral sampling. Sociological Methods and Research, Thousand Oaks, v.10, n.2, p. 141-163, 1981.

BLIEVERNICHT, A.; IRRGANG, S.; ZANDER, M. Sustainable Sphagnum production to replace peat in commercial horticulture. Gesunde Pflanzen, Wheinheim, v. 62, n. 3-4, p. 125-131, 2011.

BORGER, G. J. Peatland exploitation in the low countries. The Hague: SPB Academic Publishing, 1990, 21p.

BULLOCK, A.; ACREMAN, M. The role of wetlands in the hydrological cycle. Hydrology and Earth System Sciences, Delft, v. 7, n. 3, p. 358-389, 2003.

CAMPEAU, S.; ROCHEFORT, L. Sphagnum regeneration on bare peat surfaces: field and greenhouse experiments. The Journal of Applied Ecology, London, v. 33, n. 3, p. 599-608, 1996.

CHAPMAN, S.; BUTTLER, A.; FRANCEZ, A.; LAGGOUN-DÉFARGE, F.; VASANDER, H.; SCHLOTER, M.; COMBE, J.; GROSVERNIER, P.; HARMS, H.; EPRON, D.; GILBERT, D.; MITCHELL, E. Exploitation of northern peatlands and biodiversity maintenance: a conflict between economy and ecology. Frontiers in Ecology and the Environment, Washington, v.1, n. 10, p. 525-532, 2003.

CHARMAN, D. Peatlands and environmental change. Chichester: John Wiley Sons, 2002. Chichester. 2002, 301p.

CRUM, H. A. North American Flora: Sphagnopsida Sphagnaceae. New York: The New York Botanical Garden, 1984, 180p.

CUNHA, L. H. Da “tragédia dos comuns" à ecologia política: Perspectivas analíticas para o manejo comunitário dos recursos naturais. Revista Raízes, v. 23, n.1 e 2, p.10-26, 2004.

DIAS, E.; MENDES, C. Ecologia de algumas espécies de Sphagum da Ilha Terceira. 2005. Disponível em: www.angra.uac.pt/GEVA. Acesso 22 de março de 2012.

DÍAZ M. F.; ARMESTO, J. J. Limitantes físicos y bióticos de la regeneración arbórea en matorrales sucesionales de la Isla Grande de Chiloé, Chile. Revista Chilena de Historia Natural, Santiago, v. 80, n.1, p. 13-26, 2007.

DÍAZ M. F.; BIGELOW, S.; ARMESTO, J. J. Alteration of the hydrologic cycle due to forest clearing and its consequences for rainforest succession. Forest Ecology and Management, Melbourne, v. 244, n.1-3, p. 32-40, 2007.

DÍAZ, M. F; LARRAIN, J.; ZEGERS, G.; TAPIA, C. Caracterización florística e hidrológica de turberas de la Isla Grande de Chiloé, Chile. Revista Chilena de Historia Natural, Santiago, v. 81, n. 4, p. 455-468, 2008. 
DORREPAAL, E.; AERTS, R.; CORNELISSEN, J. H. C.; VAN LOGTESTIJN, R. S. P.; CALLAGHAN, T. V. Sphagnum modifies climate-change impacts on subarctic vascular bog plants. Functional Ecology, London, v. 20, n. 1, p. 31-41, 2006.

DUMORA, C. Viver e sobreviver numa Área de Proteção Ambiental: o caso da pequena agricultura familiar em uma das comunidades rurais da APA de Guaraqueçaba. Desenvolvimento e Meio Ambiente, Curitiba, v. 14, p. 47-67, 2006.

FERREIRA, M. R. Comunidades rurais de Guaratuba-Paraná: os limites e as possibilidades da opção extrativista como meio de vida no contexto do desenvolvimento rural sustentável. Curitiba, UFPR, 2010, 222p. Tese (Doutorado em Agronomia)

FERREIRA, I. T.; SOUZA, J. A; ROCHA, M. T. R.; VIÉGAS, J.; SILVA, J. B. Violetas-africanas micropropagadas: cultivo em diversos substratos. Revista Brasileira de Horticultura Ornamental, Campinas, v. 7, n. 2, p. 109-116, 2001.

FERREIRA，M.R.; NEGRELLE，R.R.B.; ZANATTA, R.A.F. Terra inválida, gente invisível: o caso das comunidades rurais extrativistas do litoral paranaense. In: FRIGO, V.D.; ABRAHÃO, C.M.S.; QUADROS, D.A. (orgs). Litoral do Paraná: reflexões e interações. Matinhos: Editora UFPR Litoral,. p. 13-38, 2011.

GLIME, J. M. Bryophyte Ecology. Ebook v. 5. Uses. Houghton: Michigan Technological University and the International Association of Bryologists. Disponível em http://www.bryoecol.mtu.edu. Acesso. 12 março 2009.

GORHAM, E. Northern peatlands: role in the carbon cycle and probable responses to climatic warming. Ecological Applications, Ithaca, v. 1, n. 2, p. 182-195, 1991.

GUTBERLET, J. Uso de Sphagnum recurvum P. Beauv. como biofiltro no monitoramento de poluição aérea industrial de metais pesados Acta Botanica Brasilica, São Paulo, v. 2 ,n. 1, supl.1, p.103-114, 1988.

HALLINGBACK, T.; TAN, B.C. Towards a global action plan for endangered Bryophytes. Anales del Instituto de Biología de la Universidad Nacional Autónoma de México, Ser.Bot., México City, v. 67, n. 1., p. 213-221, 1996.

HARDIN, G. The tragedy of the commons. Science, v.162, n. 3859, p. $1243-1248,1968$.

HENRIQUES, A. R. O uso do Sphagnum no biomonitoramento da poluição aérea por cádmio. Pelotas: Instituto de Biologia, UFP, 2005, 80 p. Monografia (Bacharel em Ciências Biológicas)
HODGETTS, N. G. Threatened bryophytes in Europe. Anales del Instituto de Biología de la Universidad Nacional Autónoma de México, Ser.Bot., México City, v. 67, n. 1., p. 183-200, 1996.

HOMMA, A. K. O. Extrativismo, biodiversidade e biopirataria na Amazônia. Brasília: EMBRAPA, 2008, 97p.

IBGE - INSTITUTO BRASILEIRO DE GEOGRAFIA E ESTATÍSTICA. Manual técnico da vegetação brasileira. Rio de Janeiro IBGE, 1992, 92p.

JUNKIN, R.; DONOVAN, J.; STOIAN, D.; VARGAS, E. Organización empresarial de pequeños productores y productoras - guía para facilitadores de las etapas iniciales del desarrollo empresarial rural. Turrialba, CATIE, 2005, 100p.

KEYS, D. Canadian peat harvesting and the environment. Sustaining Wetlands, Ottawa, v. 3, p. 1-14, 1992.

KUSTERS, K; BELCHER, B. (eds.) Forest products, livelihoods and conservation. Case studies on non-timber forest products systems -Asia. Bogor: CIFOR, 2004, 365p.

MCNEIL, P.; WADDINGTON, J. M. Ecohydrological controls on Sphagnum growth and CO2 exchange on a cover bog surface. Journal of Applied Ecology, London, v. 40, n. 2 , p. 354-367, 2003.

MOURA, M. M. Camponeses. São Paulo: Ática, 1986, 78p.

MOORE, P.D. The future of cool temperate bogs. Environmental Conservation, Cambridge, v. 29, n. 1, p. 3-20, 2002.

OSTROM, E. Governing the commons. The evolution of institutions for collective action. Cambridge: Cambridge University Press, 1990. 298p.

PLOTKIN, M.; FAMOLARE, L. Sustainable harvest and marketing of rain forest products. Washington, D.C.: Island Press \& Conservation International, 1992, 340p.

POULIN, M.; ROCHEFORT, L; PELLERIN, S.; THIBAULT, J. Threats and protection for peatlands in Eastern Canada. Géocarrefour, Lyon, v. 79, n. 4, p. 331344, 2004.

RAMSAR. The Ramsar handbooks for the wise use of wetlands. v. 17, 3 ed. 2007 Disponível em: http://www. ramsar.org/lib/lib_handbooks2006_e.htm. Acesso em 9 maio 2009. 
RANCURA, S. Subsídios ao extrativismo de Briófitas no Município de Cananéia, SP. São Carlos: UFSCar, 2009, 123 p. Tese (Doutorado em Ecologia e Recursos Naturais)

ROCHEFORT, L. Sphagum - a keystone genus in habitat restoration. The Bryologist, Storrs, v. 103, n. 3, p. 503-508, 2000.

RODERJAN, C.V.; GALVÃO, F.; KUNIYOSHI, Y.S.; HACHTBACH, G.G. As Unidades Fitogeográficas do Estado do Paraná. Ciência \& Ambiente, Curitiba, n. 24, p. 75-92, 2002.

ROOS, S. Raised bog restoration to peat producing Sphagnum species: an overview of European approaches. Restoration and Reclamation Review, Twin Cities, v. 1, n. 4, 1996.

SACHS, I. Inclusão social pelo trabalho decente: oportunidades, obstáculos, políticas públicas. Estudos Avançados, São Paulo, v. 18, n. 51, p. 23-49, 2004.

SANTILLI, J.F.R. Socioambientalismo e novos direitos: proteção jurídica à diversidade biológica e cultural. São Paulo: Peirópolis, 2005, 303p.

SAXENA, D. K.; HARINDER. Uses of Bryophytes. Resonance, v.9, n.6, p.56-65, 2004.

SCHRECKENBERG, K.; RUSHTON, J.; TE VELDE, D. NTFP value chains: what happens between production and consumption? In: MARSHALL, E.; SCHRECKENBERG, K.; NEWTON, A.C. (eds.). Commercialization of nontimber forest products: factors influencing success. Cambridge: UNEP/ WCMC, 2006, p. 97-106.

SHARP, A. J.; CRUM, H.; ECKEL, P. The Moss Flora of Mexico. Memoirs of the New York Botanical Garden, New York, v. 69, p. 1-111, 1994.

SILVA, M.S.; PEREIRA, J.C.O “virador”: estilo de sobrevivência do empreendedor brasileiro. Revista Científica da FAI, Santa Rita do Sapucaí, v. 7, n. 1, p. 62-71, 2007.

SILVEIRA, C.T.; FIORI, A.P.; OKA-FIORI, C. Estudo das unidades ecodinâmicas de instabilidade potencial na APA de Guaratuba: subsídios para o planejamento ambiental. Boletim Paranaense de Geociências, Curitiba, n. 57, p. 9-23, 2005.

SIMPSON, D.; CHRISTENSEN J. R., N. L. Human activities and ecosystem function: reconciling economics and ecology. New York: Chapman-Hall, 1996, 297p.

SINGER, P. Aprender economia. São Paulo: Contexto, 2001, 208p.

SOLBRIG, O. T. From genes to ecosystems: research agenda for biodiversity. Cambridge: IUBS, 1991, 124p.
SONDA, C. Comunidades Rurais Tradicionais da Área de Proteção Ambiental Estadual de Guaratuba: Caracterização socioeconômica e utilização dos recursos vegetais silvestres. Curitiba, UFPR, 2002, 193p. Tese (Doutorado em Ciências Florestais).

SOUZA NETO, B. Contribuição e elementos para um metamodelo empreendedor brasileiro: o empreendedorismo de necessidade do "virador”. São Paulo: Blucher Acadêmico, 2008, 314p.

SYLVESTER, O.; AVALOS, G. Cultural dynamics and associations of palm heart wild illegal extraction from Geonoma edulis in Montane Zones of Costa Rica's National Parks. Economic Botany, St. Louis, v. 63, n. 2, p. 179-189, 2009.

TICKTIN, T. The ecological implications of harvesting non-timber forest products. Journal of Applied Ecology, London, v. 14, n. 1, p. 11-21, 2004.

TOUSIGNANT, M.; PELLERI, S.; BRISSON, J. The relative impact of human disturbances on the vegetation of a large wetland complex. Wetlands, London, v. 30, n. 2, p.333-344, 2010.

TUBA, Z.; SLACK, N. G.; STARK, L. R. Bryophyte ecology and climate change. Cambridge: Cambridge University Press, 2011, 528p.

VALENZUELA-ROJAS, J.; SCHLATTER, R. Las turberas de la Isla Chiloé (X Región, Chile): aspectos sobre usos y estado de conservación. In: BLANCO, D. E.; BALZE, V. M. (eds). Los turbales de la Patagonia - bases para su inventario y la conservación de su biodiversidad, Buenos Aires: Wetlands International, p.87-92, 2004.

VAN SETERS, T.; PRICE, J. The impact of peat harvesting and natural regeneration on the water balance of an abandoned cutover bog, Quebec. Hydrological Process, Malden, v. 15, p. 223-248, 2001.

VELOSO, H. P.; RANGEL FILHO, A. L.; LIMA, J. C. A. Classificação da vegetação brasileira, adaptada a um sistema universal. Rio de Janeiro: IBGE, 1991, 92p.

WHINAM, J.; BUXTON, R. Sphagnum peatlands of Australasia: an assessment of harvesting sustainability. Biological Conservation, Boston, v. 82, p. 21-29, 1997.

WHINAM, J.; HOPE, G. S.; CLARKSON, B. R., BUXTON, R. P.; ALSPACH P. A.; ADAM, P. Sphagnum in peatlands of Australasia: their distribution, utilization and management. Wetlands Ecology and Management, Secaucus, v.11, p. 37-49, 2003. 
WICHTMANN, W.; JOOSTEN, J. Paludiculture: peat formation and renewable resources from rewetted peatlands. International Mire Conservation Group Newsletter, Greifswald, n. 2007-3, p. 24-28, 2007.

YANO, O. Briófitas. In: FIDALGO, O.; BONONI, V.L.R. (eds.). Técnicas de coleta, preservação e herborização de material botânico. São Paulo: Instituto de Botânica, São Paulo, 1989. p. 27-30.

YANO, O.; PIRANI, J. R.; SANTOS, D.P. O gênero Sphagnum (Bryopsida) nas regiões Sul e Sudeste do Brasil. Revista Brasileira de Botânica, São Paulo, v. 8, p. 55-80, 1985. 